\title{
Technicians and Dentists: A catch 22 situation?
}

\author{
SADJ August 2021, Vol. 76 No. 7 p432 - p434
}

LM Sykes', C Bradfield², GP Babiolakis ${ }^{3}$, L Becker ${ }^{4}$

\section{ABSTRACT}

Dental technicians who regularly receive poor quality impressions and records are often faced with professional and ethical concerns as to how to handle the situation. They may choose to complete the task to the best of their abilities. Other options are to alter the casts to try to improve the situation and then complete the prescription, contact the dentist and discuss the issue, contact the patient, contact the medical aid, report the practitioner to the HPCSA, or refuse to do the work.

Their latter actions have potentially negative implications for them, and will certainly sour working relationships. At worst, they may lose the dentist's support. This paper explores ways in which dentists and techniciains can foster collegial and mutually beneficial relationships from early on in their careers. This will not only promote better communication, and improve the quality of work produced by them, but it will also serve the best interests of their patients and the profession as a whole.

\section{INTRODUCTION}

A previous paper ${ }^{1}$ explored the challenges dental technicians face when they are sent poor quality work and asked (instructed) to complete the case.

In addition to the many responses presented in that paper, more technicians have come forward with further ethical challenges that they are struggling to find answers to. Their main concern, and the focus of this paper is the welfare of patients. Technicians may receive poor quality work from the dentist and even identify situations where

\section{Author affiliations:}

1. Leanne M Sykes: BSc, BDS, MDent, IRENSA, Dip Forensic Path, Dip ESMEA, Head of Department of Prosthodontics, University of Pretoria, Pretoria, South Africa. ORCID Number: 0000-0002-2002-6238

2. Charles Bradfield: $B$ Tech, BChD, Dip Aesthetics, Registrar Department of Prosthodontics, University of Pretoria, Pretoria, South Africa.

3. George P Babiolakis: BDS, MScDent, PGDip Dent, Part-time Lecturer, Department of Prosthodontics, University of Pretoria.

4. Len Becker: BChD, HDip Dent (Wits), MChD (Pret), FCD (SA)., Specialist Department of Prosthodontics, University of Pretoria, Pretoria, South Africa.

Corresponding author: Leanne M Sykes

Department of Prosthodontics, University of Pretoria,

Pretoria, South Africa.

Email: leanne.sykes@up.ac.za

Author contributions:

1. Leanne M Sykes: Primary author $-55 \%$

2. Charles Bradfield: Second author $-15 \%$

3. George P Babiolakis: Third author $-15 \%$

4. Len Becker: Fourth author - 15\% adjacent teeth have been badly damaged, based on the pre-operative study models (if these exist). Figure 1 illustrates a case where the technician poured a cast from a very poor impression. It clearly shows mandibular anterior teeth with advanced alveolar bone loss, that are more than likely also mobile, as they have been splinted.

The accompanying instructions were for the technician to do a diagnostic wax up as the dentist planned to place crowns on these teeth. The technician felt very uneasy with the proposed treatment. Cases like these raise several professional and ethical concerns that put technicians in a difficult position on how to handle the situation.
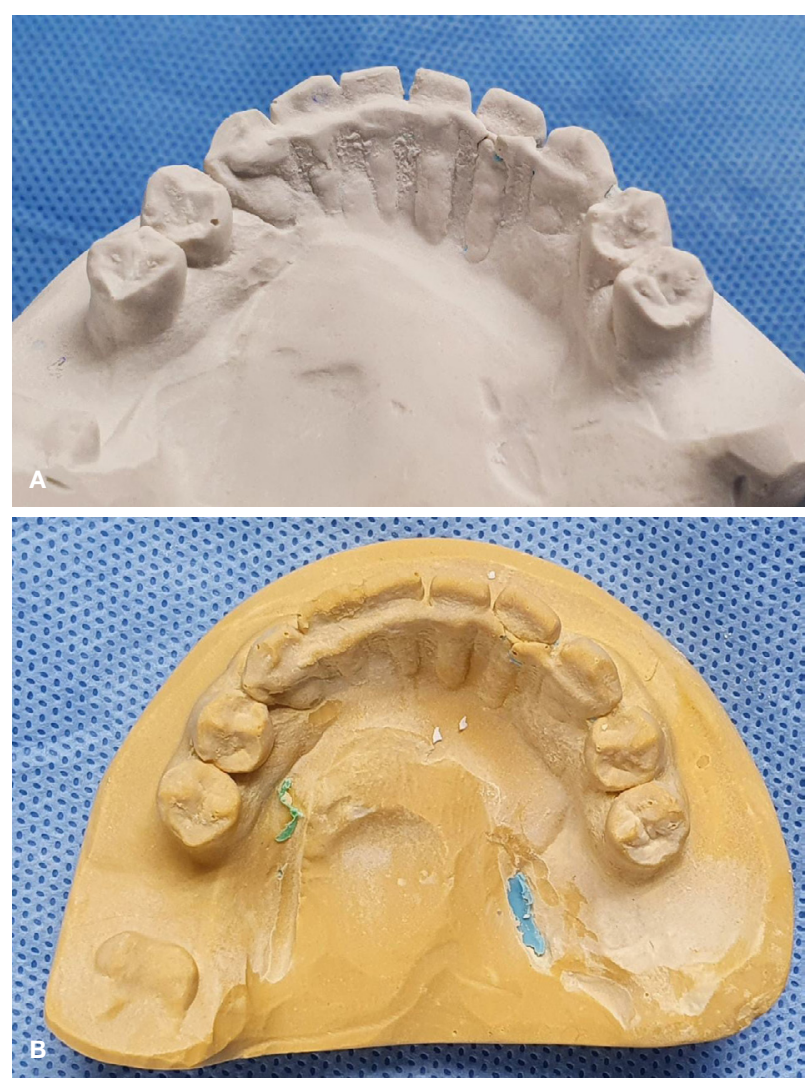

Figure 1. Cast showing splinted mandibular anterior teeth with exposed roots.

\section{Concerns}

The technician may feel that the patient has been badly treated and would like to alert them to this. However, the dentist will argue that the clinical situation was more complex than the models suggest, which necessitated additional tooth structure being sacrificed. 
Technicians know that indirect restorations made on poorly prepared teeth will not meet professional standards and are doomed to fail, and yet they are still being expected to spend (waste) their time fabricating these restorations. This goes against the ethics of fair distributive justice..$^{2,3}$

They may be concerned that the patient could suffer further harm if these restorations fail. The "harm" in this sense may include pain, discomfort, embarrassing aesthetics, the inconvenience of needing to have the work re-done, additional time and financial costs, and even possible tooth loss.

The dentist and patient could blame the technician for the failures and technicians have no way to prove that this was not the case. Also, they are often expected to re-do the work at their own expense, which can be a substantial time and financial burden.

\section{Possible actions}

1). Their first line of action will be to carry out the work to the best of their abilities. They will most likely feel uneasy about this and constantly be on edge about the possibility that the case will fail within a short period.

Some have even resorted to "altering the casts" to try and improve them and then completing the case. Their anxiety and moral conscience may well rule out this option.

2). Secondly, they could contact the dentist and discuss the case. If it is a once-off they may be able to reach a compromise and will probably try their best to remedy the situation together.

3). If it is a repeat occurrence it becomes a bigger concern, especially if the dentist has been approached and does not improve, or if the dentist refuses to accept that his/her work is substandard. In this case, can/should they inform anyone else, and if so, who?

a). Can a technician contact the patient directly and tell them about their reservations? Do they have a right to do this seeing as their primary client is the dentist and not the patient? However, the "end-user' is the patient and they will be the ones who suffer. Could they be sued by the dentist for defamation of character if they do talk to the patient?

b). Should the technician rather contact the medical aid and tell them that this clinician repeatedly sends poor quality work and perhaps hope the medical aid will investigate the number of times they get "double accounts" for work on the same patient. It may also reveal if the dentist may be fraudulently submitting the second account with different tooth numbers to ensure they get paid, which is an even greater offense and can have medico-legal consequences.

c). Should they report the practitioner to the HPCSA and if so on what grounds? Rule 26 of the Councils relates to reporting of "impaired "colleagues. However, "bad work" is not necessarily an impairment, and how can they prove this if the patient doesn't complain? d). They may refuse to do the work and ask that it be sent to another laboratory.

\section{Potential implications}

The ethical technician who feels they have a moral duty to serve the best interests of the patients, to protect the reputation of the profession, and to maintain high standards of care may find himself or herself in a quagmire. They now have to weigh up the risks of acting according to their conscience and in the best interest of the patients, against many possible negative consequences.

The concerned technician will not be able to turn a blind eye to bad work for any length of time and will have to make a difficult decision on how to move forwards. In the second scenario where an amicable and favorable solution was reached; the outcomes and consequences will be beneficial to all parties.

In the third case, they risk angering the clinician and will probably lose the work. They may also not get sent any future work, which will compromise their livelihood.

If they contact the patient, not only will they lose work, but could open themselves up for a hefty lawsuit that could be difficult to defend. They also have no way of knowing how the patients will react to their communication and interference. There is even a risk that the patients will support the dentist, in which case they will have no grounds of justification!

Contacting the medical aids may alert them to be vigilant when assessing future claims from these practitioners. However, from an ethical standpoint, it is also somewhat self-serving and won't appease their conscience. They are still completing the work, and still ensuring they get paid for it, yet the patient is still going to be affected if it fails. Thus they cannot declare that they have acted in the best interest of THAT patient.

A further risk they need to consider very carefully is their livelihoods. The dental community is small and word of their actions will become known to other clinicians very quickly. They could find themselves being blacklisted from receiving any work from all other clients especially practitioners who worry that their work may be scrutinized and reported on.

\section{Possible solutions?}

While it is easy and tempting to criticize the work of colleagues, one needs to remember that there may have been unknown, adverse circumstances that influenced the outcomes. Nobody can produce perfect work all of the time. There will be occasions when even the best dentist or technician may produce work that the other party feels could be improved upon. The issue arises when the pattern is repeated. After discussion with other experienced technicians, they suggest to perhaps keep sending unsatisfactory work back to the dentist.

This will allow them to uphold their oath to "do no harm", ${ }^{6}$ and be at peace with their conscience knowing that they have served the patient's best interest. The patient may 
also start to question the dentist's ability to perform the work as the impression has to be continually repeated, which may in turn force the dentist to improve to avoid an embarrassing situation. However, they may lose the work in the process, and the dentist will probably continue to carry out and deliver inferior quality work.

It would be far better for all parties if dentists and technicians develop a good relationship of understanding and mutual trust and respect from the onset. They need to both appreciate the limitations and difficulties that may be encountered, as well as know what can realistically be accomplished in any given case.

Both professions need to think of possible solutions. If we don't take this on, nothing will get done and the situation will never change (or improve). A practical constructive and a mutually beneficial solution will be to implement common teaching platforms at the undergraduate level.

Technicon students could do a rotation period at one of the 4 dental schools. Here they will be allocated to a group of students for whom they will be required to carry out the laboratory work. Ideally, they will accompany their peers to the clinical wards where they will be able to appreciate some of the challenges a clinician faces. These include issues such as difficult working position, mouth access, navigating a mobile tongue, saliva, bleeding, limited mouth opening, material manipulation, difficult patients, communication problems, time constraints, and unforeseen dental complications.

While it is primarily the duty of the dentist to manage these difficulties adequately, it will help them understand why impressions and work are sometimes unsatisfactory and why it may require.additional effort to obtain an acceptable outcome. They will also have a clearer idea of issues to discuss with the clinician if they are uncertain or unhappy.

At the same time, dental students can accompany their "partner" to the laboratory and observe the technical aspects of dental technology being performed on their very own patient cases. This should help clarify and consolidate their knowledge about why certain clinical requirements and mouth preparations are needed. They will also develop more realistic expectations of what can be achieved in the dental laboratories and learn how to communicate their instructions comprehensively and understandably.

We must strive to instill a culture of dentists and technicians being a united team, from an early stage in career development, and that we need each other and need to work with each other. Understanding each other will allow both parties to produce better work in the future.

Perhaps the movement to digital technology where clinicians scan, design and make indirect restorations themselves, will allow them to appreciate the difficulties a technician may have with unsatisfactory preparations and impressions. Some software programs also have a "prep checker" which can be used to analyze the preparation and provide an "unbiased evaluation" of it. This too enables clinicians to assess their work at the chairside and make the necessary corrections within that same visit.

\section{Conclusions}

This paper highlights the need to develop an ethos where dentists and technicians have a convivial relationship and are willing and able to discuss cases openly, and reach workable solutions or at the very least, an appropriate compromise.

They should also be willing to give and receive constructive criticism with the spirit that it is intended. This will not only improve the quality of work they produce and deliver but will help ensure the best possible outcomes for their patients. A win-win-win situation.

\section{References}

1. Gilyoma JM, Rambau PF, Masalu $\mathrm{N}$ et al. Head and neck cancers: a clinic-pathological profile and management challenges in a resource-limiting setting. BMC Res Notes. 2015; 8: 772 .

2. Davis TC, Williams MV, Marin E, Parker RM et al. Health literacy and cancer communication. A Cancer Journal for Clinicians. 2002; 52(3): 134-49.

3. De Sousa A. Psychological issues in oral and maxillofacial reconstructive surgery. Science Direct. 2008; 46: 661-4.

4. Moodley $\mathrm{K}$ and Naidoo S. Ethics and the dental team. Pretoria, Van Schaik publishers. 2010. 38-41.

5. Beauchamp TI, Childress JF. Principles of Biomedical Ethics. $5^{\text {th }}$ Ed. New York: Oxford University Press. 2001.

6. Levine E, Degutis L, Pruzinsky T. et al. Quality of life and facial trauma: psychological and body image effects. Ann Plas Surg. 2005; 54: 502-10.

7. Reed J, Robathan M, Hockenhull M, et al. Children's attitudes towards interacting with peers with different craniofacial anomalies. Cleft Palate Craniofac J. 1999; 36: 441-7.

8. Constitution of the World Health Organization. In: World Health Organization: Basic documents. $45^{\text {th }}$ ed. Geneva: World Health Organization. 2005.

9. Sartorius N. The meanings of health and its promotion. Croat Med J. 2006; 57(4): 662-4.

10. Twigg JA, Anderson JM, Huphris G, et al. Best practice in reducing the suicide risk in head and neck cancer patients: a structured review. British Journal of Oral and Maxillofacial Surgery. 2020; 58: e6-e15. 